\section{Eyewitness Accounts on Climate Variability and the Responses: Perspectives from Farmers}

\section{Jiban Mani Poudel}

\begin{abstract}
People with different socio-cultural arrangements have different experiences and responses to climatic variability. The place specific experiences and responses at community level still remain a little explored issue in the discourse of climate change research. This paper deals with local experiences of climatic variability which have been monitoring by locals in their lifetime, on the one hand, and, on the other, explore their responses or coping mechanisms which they have been practicing to mitigate with climatic risks. Moreover, farmers' experiences were documented in term of observed climatic variability in their lifetime focusing on qualitative data. I have used eyewitness accounts and hearsays to document their experiences of climatic variability. Moreover, farmers have developed various coping mechanisms such as indigenous knowledge, utilize kinship based social network, environment friendly cropping practices, and use of alternative sources of water (water-tanker, well-water) for irrigation, arrange rain-making ritual to cope with climatic uncertainty in their lifetime.
\end{abstract}

Keywords: Farmer, climatic variability, experience, response, coping mechanism

\section{Introduction}

Human societies have been facing extreme events, such as droughts, floods, hurricanes, storms etc. and also dealing with them for the age. Paleo-anthropologists, archeological anthropologists and archeologists have given ample evidences about it (Bogin 1982, Nelson and Jurmain 1988, Wenke 1990). Although the term climate change has become a public, political and academic buzzing word in the beginning of the $21^{\text {st }}$ century in global context (Broad and Orlove, 2007; Gidden, 2008). Anthropologists, especially ecological anthropologists are also not remained themselves isolate from the issue. But they have given their more attention to document knowledge and perceptions of local people (Vedwan and Rhoades, 2001; Vedwan, 2006; Crate, 2008; Poudel, 2011a,) and the issue of adaptation and coping mechanism with climatic uncertainty is still not remaining less priority for academician (Jacka, 2009; Green, 2009; Henshaw, 2003; Hitchcock, 2009). In some literature, it (adaptation) remains as a predominant word, but not properly addressed the issue in the content (Adger et al., 2006; Biggs et. al, 2012).

The experiences to weather fluctuation and climate change may not be same and the responses may be varied. It may be varied from region to region, society to society even household to household as well as individual to individual. Thus, it is needed to carry out place-specific analysis of adaptation to climate change in the present day world. This is because the inevitable surprises of climate change will unfold on a regional and local stage where adaptive response becomes central (Holling, 1997 as cited in Berkes and Jolley, 2001). To carry out ethnographic studies suited in a specific place and cultural group is essential for better understanding to the dynamic interaction between nature and society. Because weather fluctuations and ongoing climatic change might have brought some opportunities for some people and region and threaten to others (Berkes and Jolley, 2001; Hassan, 2009). In the case of Kathmandu valley, climatic uncertainties might have more threatening than opportunities to the local peoples' life. In this context, farmers have been developing several coping mechanisms in spite of threat created by climatic uncertainty. My aim, in this paper, is to understand how farmers are cognized to climate variability and what their responses are. In this context, this paper will try to answer the questions: how and what have farmers been experiencing of climate variability? Are there any differences on experiences and responses of people according to their different socio-cultural 
arrangements? What have been their coping mechanisms in the past/recent climatic uncertainty? These questions are simple but critical for answers from the viewpoint of social scientists.

\section{Anthropological perspectives on climate change}

The events of weather fluctuation and climate change can generally be understood through two ways i.e., bio-physical manifestation of environment change, and culturally shaped frame (Roncoli et al., 2002; West and Vasque-Leon, 2003, Orlove et al., 2008; Poudel, 2011a). The first perspective is commonly used and analysed by modern natural science, known as meteorological analysis. Their analyses are long-term (years, decades, century and more) and cover the broader regions like regional and global geographical areas. Thus, identifying the cause and nature of climate change, and assessing its impacts is still claiming by natural scientists as their legitimate prerogative (Duerden, 2004 cited in Crate and Nuttall, 2009). On the contrary, the second perspective is an interpretive or ethno-perspective that focuses on actor's or insider's perspective in which people use their own experiences, observation, eyewitness accounts, local stories, myths, folklore, religious beliefs, and so on to explain the weather fluctuations and climatic variability in their local context. It rests on cognition, and is also shaped by cultural frame in the given context with subjective and contextual meanings (West and Vasquez-Leon, 2003; Roncoli et al., 2003; Crate, 2008; Poudel, 2011a, 2011c). Moreover, it is impossible to study from descriptive perspective (Roncoli et al. 2009), as well as operational model (Rappaport, 1979). Therefore, anthropologists argue that the second perspective is more significant to understand how local people experience, perceive, and interpret the weather fluctuation and climate change at community level (Orlove et al., 2008, Crate and Nuttall, 2009).

Anthropologists argue that all human beings have developed cognized capacities to recall the past (Orlove and Strauss, 2003; Vedwan, 2006). It is shaped by observed events of individuals during their lifetime and is based on culture and cultural perspective. Therefore, recalling the past events may vary among culture and cultural perspectives as well as observation of individuals within their lifetime in a same cultural group. However, anthropologists argue that local people cannot remind all events but remember extreme events only that have occurred in their lifetime (Vedwan and Rhoades, 2001; Vedwan, 2006; Poudel, 2011a). In other words, farmers' experiences about climatic fluctuations do not rest on bio-physical manifestation of environmental phenomena but they are embedded with cognized knowledge associated with extreme events that have direct relation with crops and livestock management (Roncoli et al., 2003; Poudel, 2011a). In this sense, Rappport argued that there is a difference between cultural images of nature and the actual organization of nature which is the central problem of human beings that ecological anthropologists concern to understand (1979:97). He further stated that nature is seen by humans through a screen of beliefs, knowledge and purposes rather than actual structure of nature state. This model is called cognized model in ecological anthropology (Rappaport, 1979:97). Agreeing with this model, I also argue that we can document weather fluctuation and climate change by locally grounded knowing and seeing the events in the local context rather than ignoring them.

Human adaptation has been the central issue of study in ecological anthropology since last six decades. In field of weather and climate studies, human experiences, perceptions, knowledge, impacts and responses have been the subject of socio-cultural anthropology over the past one decade. In this paper, I focus to analyze the coping mechanism than adaptation while examining the responses of farmers at community level. Coping mechanism, here I mean, is short term actual response to change. However, the phrases 'adaptive strategies' and 'coping mechanism' are synonymously used in anthropological literature (McCay, 1978) and development literature (Davies, 1993). Adaptive strategies are considered as processes rather than an end stage (Fricke, 1993; Bennett, 1996; Berkes and Jolley, 2001). It is an outcome of long-term change in total ways of life of individuals, households and communities. In another way, adaptive strategies are the ways in which individuals, households and communities change their productive activities and modify their local rules and regulations as well as institutions to secure livelihood over the larger period (Berkes and Jolly, 2001). The motion of change in adaptive strategies is quite slow which is closely embedded with cultural value of communities and cover 
the wider spatial spaces. On the other hand, coping mechanisms are short term resilience or responses to situations that threaten the livelihood systems of individual, households and communities. It is also called the emergency response in abnormal seasons or year (Berkes and Jolly, 2001). The coping mechanism may develop at individuals and households level and at smaller spatial scales. Such coping mechanism may develop into adaptive strategy over time.

The study focuses on responses of farmers by relating with framing practices and weather fluctuation and climate change over few years. The people live in mixed economy like subsistence agriculture, service and other non-agricultural activities due to being located nearby capital of the country. However, most of the people are still depending on subsistence agriculture like paddy plantation in summer season and wheat and mustard seed in winter season for their livelihood. However, the farmers have been experiencing the fluctuation on weather and climate patterns in their surroundings over the last few years which is threatening their agricultural practices, on one hand, and, on the other, they have developed certain short term responses like use of water tank, well water and ground water for irrigating the field during plantation period, diversify the cropping pattern, exchange of seeds, begin to alternative cropping as a coping mechanism with the challenges created by climate change in their surroundings.

\section{Site and Method}

This study was carried out at Kirtipur of Kathmandu valley. There were several reasons behind the selection of this area for the study. Firstly, agriculture in the study area tends to be largely depended on seasonal rainfall. Secondly, researcher also observed low precipitation, shifting agricultural calendar as well as new coping mechanism such as use of drinking water tank for watering the paddy field during its plantation period. Given this, this area was considered suitable study site for a better understanding of farmers' experiences and their responses of climatic variability, especially in little and delay precipitation. Finally, in this context how farmers were coping with the threat created by climatic uncertainty is an important research question by itself. The researcher has used eyewitness accounts, a technique of data collection in oral tradition, a major tool to collect information from the field. Likewise, I made several visits to the field site in 2011 and documented several eyewitness accounts of different farmers (including male and female, young and old) to document their experiences on climatic fluctuations which they have been monitoring in their lifetime in one side, and, on the other, their coping strategies to response with climatic uncertainty in the area.

\section{The Setting}

This study was conducted at Khatri-chhap of Kirtipur located at the south-western region of Kathmandu valley. The local classified the land structure into three categories on the basis of availability of water, moisturized of soil and land. The south-western part was slightly wet and highly moisturized due to its location at the bottom of the hill which is called Sim, meaning wet-land. The area has sufficient water and a number of water sources which were used to irrigate the paddy fields for plantation in the summer. Due to the highly moisturized land, paddy plantation was held between $2^{\text {nd }}$ and $3^{\text {rd }}$ weeks of May. Delay in plantation caused immature and unripe paddy. In winter, the land remained fallow. The middle part of the area is called tar -flat land. The settlements are located in the area. It is drier than Sim and Bhadkhalo. In the summer season, farmers grow paddy, maize, vegetables, and in the winter they grow vegetables, mustard seeds and wheat. Agriculture production depends largely on seasonal rainfall. Paddy plantation begins after the heavy rainfall in the summer season. The northern part of the area is called Bhadkhalo, meaning flat and lowland. This area is used for paddy plantation in the summer season, and wheat in the winter. The recent migrants have started poultry farms based on leasehold. Like the middle part of the area, agricultural production relies on season rainfall. Generally, they plant paddy from the $3^{\text {rd }}$ week of May to the $1^{\text {st }}$ week of June due to low moisturized land. The harvesting is also done 15 days earlier in both tar and Bhadkhalo than in the sim area.

The study area is heterogeneous in term of caste and ethnic compositions. There are Chhetri, Thapa-Magar and Newar. The settlements are located in clusters. However, each caste and ethnic 
group has their own clustered settlements separated by a small muddy corridor. Households follow multiple economic strategies such as farming, livestock management, business and service. Young males generally work away from home, while females and old males are involved in farming and livestock management. During my field observation, I found that most of males were playing cards in office holidays by gathering in the local tea-shop whereas females were busy in the farms either planting paddy or weeding paddy fields, and collecting ground-grass.

\section{Responses to climatic uncertainty}

In a normal year, in Kirtipur, farmers broadcast paddy seed from $3^{\text {rd }}$ to $4^{\text {th }}$ weeks of May and transplant within a month i.e., before $15^{\text {th }}$ Asar ( $30^{\text {th }}$ June). Farmers reported that, 22-30 days old seeds are 'good', from the plantation viewpoint and more than that is 'poor'. Due to dependence on rain-fed agriculture, timing of seeding transplantation relies on the duration i.e. timing and nature of beginning of the rainy season. It is the key parameter through which they understand and evaluate precipitation (Poudel, 20011a). In other words, farmers categorized the duration of rain as 'meaningful', and 'meaningless' in terms of their observations of plant-climate interaction, rather than by precipitation measure per se (Roncoli et al., 2003:190).

For Kirtipur farmers, weather fluctuation is not a new phenomenon. Elder farmers can recall several climatic fluctuations that occurred in the past, including those of delay, erratic, little or heavy precipitation/snowfall, early arrival of cold day in their life time. They usually referred to events that are associated with weather fluctuations. One farmer told about unusually dry and fierce in 1941 and could not be able to plough and sow and another recalled the heavy snowfall in 1944/45. At that event, villagers removed the snow from their roofs. A farmer said the government fined those farmers who did not grow any crops, even lentils in farming land during the drought of 1945. Another recalled the earlier arrival of cold days in 1957 by recalling unripe paddy event, and another remembered the event of borrowing paddy seeds from relatives during the drought of 1982 . In this way, farmers recalled the extreme natural hazards which had occurred in their lives which are the most common methods to discuss the change in weather or climate pattern (Roncoli, 2006; Vedwan, 2006; Poudel, 2011a).

As a discourse raised by media and government/non-government organizations in recent days, the experiences of local people clearly indicate that weather fluctuations are not new event for Kirtipur farmers. These changes have been affecting subsistence farming activities, especially transplanting agricultural activities in the past. To resilience with short-term weather fluctuations or climatic variability in their surroundings, farmers have been developing several mechanisms to cope with climatic risks. While asking the question about the resilience with the climatic variability in the past, one elderly farmer said:

In the past, our ancestors had made a large numbers of ponds on the flat tops of the hills. Many canals came out from those ponds and ended to our farming land. When I was child, we (farmers) used the water collected in the catchments for watering winter-crops like wheat. Sometimes rain would not on set on time in the summer season and we would use water reserved in the ponds for irrigation of the field. But now-a-days, nearly all water reservoir tanks were encroached by government, community, or local clever people and converted into settlement or community buildings and remaining are also filled with mud, sand and waste materials. Now, we have great problem in drought year to transplant paddy in the summer and wheat in the winter (Bhaikaji Maharjan, 74).

This statement clearly indicates one of the indigenously developed methods to encounter with climatic uncertainties in the past. Such systems or mechanisms, said by the informants, have been gradually disappearing due to the negligence of government mechanism as well as unconsciousness of local people.

When I asked the same question, another old man narrated his experiences about delay and little rainfall and the responses followed by the community to mitigate with the risks. He said: 
The summer in 1945, it had been unusually dry and fierce. There was a huge shortage of water due to a long drought. People would not be able ploughing and sowing the field. In some area, there would be shortage of necessary drinking water for human beings as well as animals in the upland. During that time, the government had made order to plant any crops even lentil in paddy field. Some farmers had followed the order of the government and some denied it. Later, the government punished those framers who did not follow the order by fine double tax, and rewarded those who followed the order by making the free of tax (Kaji Singh Khatri, 78).

This statement clearly indicates that government also enforced order to the citizens to cope with climate uncertainty or weather fluctuation in the past and farmers would also follow it. In this way, the role of external agency was important in the past for coping with challenges imposed by climate variability.

Similarly, during the field observation, it was found that Kirtipur farmers tended to have a strong and complex social fabric based on kins and neighborhood. To cope with risks brought by environmental changes, they exchanged foods and seeds among kins and neighbors. During the fieldwork, some farmers shared their experiences about little, low and erratic rainfall in the past and loss of seeds for coming years. Under this condition, they shared seeds and cereal to each other to mitigate with climatic risks. In this regards, an elderly male respondent (84 years old) said.

In 1982, the god forgot to give water. Rainfall did not take place on right time. All paddy seedlings became dry and finally died due to horrible drought. We (farmers) were able to plant a single paddy-seedling in upland (dhalpa). That year, I borrowed paddy seeds from my relative who lived in Tokha. I returned two times greater amount cereal to him the next year.

This is not a general statement about the drought but clearly shows a climatic fluctuation event which farmers have been experiencing in their lifetime. Moreover, it also narrates the tradition of food exchange practice through which farmers coped with seeds/food crisis during the years of natural calamities. Such types of sharing or exchange of seeds/foods during crisis period commonly existed in other societies (Jacka, 2009) and very important among the traditional farming society, especially subsistence farming societies for their survival (Berkes and Jolly, 2001). And social networks for sharing tend to seem as adaptive or coping mechanism in terms of providing mutual support and minimizing risks (Chhetri, 1995; Messerchmidt, 1976) including climatic induced risks in the case of Kirtipur farmers.

Over the last six years, farmer have been observing erratic, low and delay in rainfall which continuously shift paddy plantation behind than normal time. During my field observation in 2010, some farmers were planting paddy on $29^{\text {th }}$ July and seedlings were about two months old which was poor from a plantation viewpoint ${ }^{1}$. The plantation of poor seedling leads to delay in greenery and high rate of dying of seedlings in the field, reduce reproducing capacities of mother seedlings, increases bushes and small grasses, diseases, sprout and ripe unevenly, and reduces in quality and quantity of production, size of seeds, hay etc. The untimely and low rainfall requires that farmers need to invest more labor for plantation, weeding, protection of crops form harmful pests. A farmer narrated his experiences about the fluctuation of precipitation and his response to it in the year 2009. He said:

Since the last 5 years, the rainfall has been erratic and shifting behind normal time. In 2009, some precipitation occurred in the beginning of summer i.e., $3^{\text {rd }}$ and $4^{\text {th }}$ weeks of May. We prepared bed for paddy seeds and broadcasted it. After broadcasting, seedlings were gradually growing up as a natural process. Rains did not fall about one and half month. Seedlings gradually began to die in the bed. To resilience with drought, we (farmers) watered seedlings carrying water in buckets and pots.

But in the study area, watering the paddy seedlings carrying water in buckets and pots is not new coping strategy adopted by farmers. During the low or little rainfall, farmers commonly used such

\footnotetext{
${ }^{1}$ According to DHM record from Thankot station, it was the highest rainfall day in 2009
} 
method and during the drought period also to mitigate with climatic risk in the past. In this regards, a female farmer from Newar community shared similar experience of the past. According to her:

Until the last few decades, we (farmers) would use local cannel for irrigation of the paddy field especially lowland and $\operatorname{sim}^{2}$ (wet land). But, people could not plant upland until the good rainfall. In 1982, precipitation did not fall on time i.e., in $\mathrm{Asar}^{3}$. We planted paddy in sim and lowland by using cannel water but it was not possible to irrigate the upland. We waited for a long time but the rainfall did not set on time. At last, we carried water in muddy pot and sprinkled to field and then transplanted paddy.

These are not general statements about the delay or low rainfall but clearly show the farmers' observation and experiences about climatic fluctuations in particular geographical area in different time period. Moreover, such experiences also clearly reveal that climate fluctuations are not new events in the study area. It means, farmers have been observing it in certain time interval. Similarly, these statements also tell about how local responses to cope with climatic uncertainty.

Farmers informed that impact of climate change is not same for all varieties of plants of crops. The farmers perceived that paddy would be greatly affected by delay rainfall and very little rainfall in summer whereas maize was not affected. Therefore, some people from Kirtipur started maize or millet plantation in the sloppy land locally called dhalpa as well as in the paddy field in the year 2009 and 2010. A young farmer explained the change in crop plantation in his field like this:

Until the last five years, rainfall would occur on time. We (farmers) would begin paddy plantation from the $2^{\text {nd }}$ week and completed in the $3^{\text {rd }}$ week in June. However, the

\footnotetext{
${ }^{2}$ Farmers still use cannel for irrigation the field during the paddy plantation

${ }^{3}$ It was the lowest precipitation year in Kathmandu according the DHM record from Thankot Station
}

duration of rainfall has gradually shifted, the rainfall days have been reduced, and an amount of rainfall was also low. Until the last three years, we planted paddy quite late than the normal time by using small iron spade. It ultimately increased the demand of labour and increased extra economic burden for plantation. In 2009, I planted millet in dhalpa land (sloppy land). In 2010, I planted maize due to delay in rainfall. In 2011, I planted paddy due to good rainfall in time.

In the study area, it was found that local farmers had detailed local environmental knowledge and skill about timing of seasonal harvest cycles as well as alternative of cereal crops. Such wider and detailed knowledge about the bio-physical environment had given incentive for individual to diversify crop varieties to cope with uncertainty created by natural calamities such as weather fluctuation in their surrounding. In the case of Kirtipur, most of the households followed multiple cropping patterns such as paddy, maize, wheat, mustard seeds, green vegetable production. Recently, some households began poultry farming. Such diversification is well known as a risk bearing strategy related to uncertainty to climatic variability (Berkes and Jolly, 2001). In this regard, an elderly woman said when I asked about mitigation strategy that they had followed in the past:

In 2009, low, delay, and erratic rainfall could significantly reduce the productivity of the cereal crops (paddy, staple cereal crop in the region) that lead to huge food shortage for the local villagers including her. In 2010, rainfall did not take place in right time i.e., the first and second weeks of Asar (until the last of June). Then we planted maize in field where we would be planted paddy in the previous years. I could harvest a large amount of maize that year.

A similar narrative is said by another old man:

In 2009, rainy season started delay and precipitation was also low. I transplanted paddy in the dry field. But, I harvested 8 pathis ${ }^{4}$, paddy only. It was 10 time less than

$\overline{{ }^{4} \text { a volumetric unit equivalent to } 2.43} \mathrm{~kg}$ of paddy, $3.4 \mathrm{~kg}$. of wheat or maize, or $3.28 \mathrm{~kg}$. of millet; one pathi consists of 8 manas 
normal year. In 2010, precipitation did not on set on time in the summer. As a result, we had to shift our paddy plantation period later than in the previous years. We planted paddy on July 10 in a dry field, using small spades. The paddy seedlings were too old. There were bushes and green grasses in the field which we could not destroy. As a result, the paddy seedlings did not grow properly due to insufficient rainfall. Then, our family decided to plant green vegetables such as mustard seeds and radish in the field where we planted paddy before harvesting. We earned about five thousands Nepali currency by selling these green vegetables in the local market at Kirtipur.

These sayings state about the growing not just this and that crop varieties by farmers but clearly indicate wider indigenous knowledge of local farmers to cope and minimize the risks induced by climatic uncertainties in their surroundings by selective environmental friendly crops species. Such wider knowledge on environmental suitable crops plantation provides better options to mitigate with weather fluctuation and climate change in the given context.

In the study area, it was reported that some households used ground water for irrigating the paddy field during the paddy plantation. They pulled out water by using bucket or electronic motor and irrigated the land. This technique was widely used in the farming area where settlement and farming lands are not separated. Recently, some wealthier family hired water tanks and used them for irrigating the land before transplanting the paddy seedlings in the field. It was the new phenomena in the context of farming especially paddy plantation in Kirtipur. The use of well/underground water or water tank seems as short term coping strategy adapted by Kirtipur farmers to adjust with delay, erratic and low precipitation which I observed in the summer seasons of 2010. However, farmers did not take these techniques (use of tankers for watering the field and well-water) as long term and cost effective strategies to cope with climatic variability, especially drought and little or erratic rainfall due to increase in the cost of investment for plantation.
As I mentioned earlier that the impact of climate change is vary from society to society, community to community, household to household, even individuals within a same household. In the study area, livestock management such as ground grass collection was major domain of women working sphere. Several women commented on reduction of hays and shortage of ground grasses to feed cattle in winter season in the drought year. In these years, women must spend long hour or a full day travelling to collect ground grasses, on the one hand, and, on the other, compelled to purchase supplemental more hay which increase cost to the family. In this regard, a woman (age of 57) narrated her experiences about availability of ground-grasses and her response towards it like this:

In the good years, the rainfall took place on time. We (women) had no problem to collect ground grasses. It was available in our own farm land as well as sloppy land located in the surroundings of our settlement. We used to collect 3 to 4 bharis (loads) of ground grasses daily to feed our cattle when weather was good. But it is not same always. Some year, precipitation should have low, delay, and erratic which would reduce the generating capacity of ground-grasses. Basically, in winter season, the groundgrasses would be dried and died due to lack of moisturizer in soil. This was also happened in the year 2009 and 2010. Under this condition, we travelled a far distance and spent nearly a full day to collect one or half bhari of ground grasses.

Another woman also said more or less same responses to cope with scarcity of ground-grasses during the time of drought. She said:

Drought increases more burdens to women than men. We manage the cattle rather than our male members. We feed our family and go out for the collection of ground grasses to feed cattle. In the good rainy year, we collected ground grasses from our own agricultural field and forest land. But, in the drought year, grasses cannot easily available in the farmlands. The rich people buy hays but the women from poor family are forced to collect ground-grasses from far distance, i.e., more than one to two hour walks. 
These sayings clearly state that climate variability adversely affects to plant species especially edible grasses and shrubs to feed cattle. Under such condition, farmers are forced to purchase supplemental feed in the form of hay which increases cost for keeping livestock, and also increases working hours to women to collect a single load of ground grasses.

It was also found that natural events, such as low or heavy precipitation, dried up of water sources are also considered as a wrath of god/goddess. To make the gods/goddess happy, farmers would conduct rain-making rituals when rain does not occur on time. As a domination of Newar cultural practices, such rainmaking ritual was also performed by Newari people and other caste and ethnic groups, as a co-resident of the area, would also participate in the ritual. It is called 'la-py-ke-gu's . These people collectively used to worship the god Ganesh at village at first, and then Machhendra at Bungmati, Champadevi at Kirtipur, Karkotak Nag at Taudaha respectively by step and step with certain rules and regulations. The members of the processions returned home shouting the slogans, "Oh Lord Mahadev, give us rain". After returning village, they arranged the ritual of water throwing among the members of community. It was commonly believed that the rain might have come after rain-making ritual. However, farmers informed me that such rain-making ritual has been gradually waning out from the community. In this way, coping or adaptive strategies of farmers on drought did not rest on alternative economic strategies alone but cultural belief also widely shaped their responses to mitigate with climatic uncertainty in the past.

\section{Conclusion}

The data presented in the text suggest that farmers have many eyewitness accounts about the events of weather fluctuation and climatic variability in their surroundings which have been observing and facing in their lifetime. Unlike meteorological data, farmers recall and understand climatic variability or fluctuation by extreme events associated with their socio-cultural life. This

\footnotetext{
${ }^{5}$ Nepali (1965) has also described the rain-making ritual in his book “ the Newars”
}

supports the ideas that farmers have wider knowledge and various experiences about climatic variability in the local context which is subjective, cultural and contextual. For instance, male farmers explain climate variability by relating with farming activities whereas female, who are mostly responsible for cattle management in the study area, explain it in term of availability of hay or groundgrasses.

The data presented in the paper suggest that farmers of Kirtipur also have felt more threaten in their livelihood during drought years. The farmers have several experiences about crops failure, delay plantation, reduce cereal and hay productions, shortage of ground grasses due to delay on set of rainy season or no or little precipitation in winter. In this context, farmers, in rural community, develop alternative way to cope with the uncertainty based on their indigenous environmental knowledge as well as strong social fabric based on kinship or neighborhood that help the local community to mitigate with the climate risks and uncertainty in the local context. For example, the farmers follow the multiple coping mechanisms such as use of water-tank, well-water for irrigating the field, watering the seedlings by carrying water in buckets and pots, plantation of maize and vegetable in low rainfall year, exchange of seeds during the year of scarcity of seeds to adjust with climatic uncertainty. In addition to those practices farmers also rely on cultural belief i.e., rain-making ritual as coping mechanism for adjust with climatic uncertainty.

At present, the climatic variability and changes have become more crucial in agriculture research and planning. In order to implement the migration program, it is essential to study people's experiences and their indigenous coping mechanism to climatic variability in general. Therefore, farmers' environmental knowledge and skill should be promoted as well as included in decision making processes while formulating plans and programs to mitigate with climate change. Moreover, adaptive strategies/coping mechanisms must be based on the concept of locally grounded knowing, seeing and valuing the world which can be more viable than externally imposed (Roncoli et al., 2009). In this context, social scientists can be a bridge between global and local discourses about climatic variability. 


\section{References}

Adger, N., J. Paavola, S. Huq, M. J. Mace, (2006). Fairness in Adaptation to Climate Change. Cambridge: Mit Press.

Bennett, J. W., (1996). Human Ecology as Human

Behavior:Essays in Environmental and Development Anthropology. New Brunswick and London: Transaction Publishers

Berkes F. and D. Jolly, (2001). “Adapting to Climate Change: Socio-Ecological Resilience in a Canadian Western Artic Community”, in Conservation Ecology, 5(2).

Biggs, E. M., G. R. Watmough and C. W. Hutton, (2012). "Community Level Environmental and Climate Change Adaptation Initiatives in Nawalparasi, Nepal", in W. L. Filho (ed.) Climate Change and Sustainable Use of Water Resources, Climate change Management. Verlag Berlin Heidelberg. Pp. 591-609.

Bogin, B. (1982). "Climate Change and Human Behaviour on the Southwest Coast of Ecuador" in Central Issues in Anthropology. 9(1):21-31

Broad, K and B. Orlove. (2007). Channeling Globality: the 199798 El Nino Climate events in Peru, in American Ethnologist, 4(2): 285-302.

Chhetri, R. B. (1995). "Rotating Credit Associations in Capital, Credit, Saving, and Investment,” in Human Organization, 54(4):449-454

Crate S. A. (2008). Gone the Bull of Winter?: Grappling with the Cultural Implications of and Anthropology's Role(s) in Global Climate Change,” in Current Anthropology, 49(4): 569-95.

Crate S. A., and M. Nuttall, (2009). "Epilogue: Anthropology, Science, and Climate Change Policy", in S. A. Crate and M. Nuttalll (eds.) Anthropology and Climate Change: From Encounters to Actions. California: Left Coast Press. Pp. 394-400.

Davies, P. (1993). "Are Coping Strategies a Cop Out?", in Institution for Development Studies Bulletin, 24(4): 6072.

\section{8 | Jiban Mani Poude}

Fricke, T. E., (1993). Himalayan Households: Tamang Demography and Domestic Processes. New Delhi: Book Faith India.

Giddens, A. (2008). "The Politics of Change: National Responses to the Challenge of Global Warming”. www.policynetwork.net

Green D., (2009). “Opal Waters, Rising Seas: How Socio-cultural Inequality Reduces Resilience to Climate Change among Indigenous Australians”, in S. A. Crate and M. Nuttall (ed.) Anthropology and Climate Change: From Encounters to Actions. California: Left Coast Press. Pp. 218-27.

Hassan F.A., (2009). Human Agency, Climate Change, and Culture: An Archaeological Perspective”. In Crate S. and M. Nuttall (ed.) Anthropology and Climate Change: From Encounter to Action. Left Coast Press, USA. Pp 87-115.

Henshaw A. (2003). Climate and Culture in the North: the Interface of Archeology, Paleoenvironmental Science, and Oral History, in S. Strauss and B. Orlove (ed.) Weather, Climate and Culture. Oxford: Berg Pp 217-32.

Hitchcock, R. K. (2009). "From Local to Global: Perceptions and Realities of Environmental Change among Kalahari San”, in Crate S. and M. Nuttall (ed.) Anthropology and Climate Change: From Encounter to Action. Left Coast Press, USA. Pp 250-261.

Jacka, J., (2009). "Global Averages, Local Extremes: The Subtleties and Complexities of Climate Change in Paupa New Guinea”, in Crate S. and M. Nuttall (ed.) Anthropology and Climate Change: From Encounter to Action. Left Coast Press, USA. Pp 197-208.

McCay, B. J. (1978). "System Ecology, People Ecology and The Anthropology of Fishing Community", in Human Ecology. Vol. 6: 397-422.

Messerchmidt, D. A. (1976). "Dhikurs: Rotating Credit Associations in Nepal”, in J. F. Fisher (ed.), Himalayan Anthropology: The Indo-Tibeat Interface. The Hauge: Mouton Publishers, pp. 141-165.

Nelson H. and R. Jurmain, (1988). Introduction to Physical Anthropology. USA: West Publishing Company 


\section{0 | Jiban Mani Poudel}

Nepali G. S. (1965). The Newars: An Ethno-Sociological Study of a Himalayan Community. Bombay: United Asia Publication.

Orlove, B., E. Wiegandt, and B. Luckman (2008). “The Place of Glaciers in Natural and Cultural Landscapes: Environment, History and Culture as Influences on Perceptions of Glacier Dynamics", in B. Orlove, E. Wiegandt, and B. Luckman (eds.) Darkening Peaks: Mountain Glaciers Retreat Social and Biological Context. California: University of California Press. 3-19.

Poudel J. M., (2011a). “Testing Farmers' Perception of Climate Variability: A Case study from Kathmandu Valley. A Paper presented on National Conference on Water, Food Security and Climate Change in Nepal Organized by international Water Management Institute (IWMI), Department of Irrigation, Ministry of Irrigation on 23-24 November, 2011, Lalitpur, Nepal.

Poudel J. M., (2011b). "Oral Tradition in Weather and Climate Research”, in Nepalese Journal of Qualitative Research Methods Vol 5, Lalitpur (Forthcoming).

Poudel J. M., (2011c). “Local People Reading Nature’s Clues to Figure out Impeding Weather: Indigenous Knowledge on Climate Change. A Seminar Paper submitted to Dean Office of the Faculty of Humanities and Social Science, and Central Department of Sociology/Anthropology, Tribhuvan University on 23 December, 2011

Rappaport, R. (1979). Ecology, Meaning and Religion. Berkeley, CA: North Atlantic Books.

Roncoli C., K. Ingram and P. Krishen, (2002). "Reading the Rains: Local Knowledge and Rainfall Forecasting in Burkino Faso", in Society and Natural Resources, 15: 411-30

Roncoli C., K. Imgram, C. Jost and P. Krishen, (2003). "Meteorological Meanings: Farmers' Interpretations of Seasonal Rainfall Forecasts in Burkina Faso", in S. Strauss and B. Orlove (eds.) Weather, Climate and Culture. Oxford: Berg Pp 181-199.

Roncoli C., T. Crane and B. Orlove. (2009). "Fielding Climate Change in Cultural Anthropology”, in Crate S. and M. Nuttall (eds.) Anthropology and Climate Change: From Encounter to Action. Left Coast Press, USA. Pp 87-115

Vedwan N., (2006). “Culture, Climate and the Environment: Local Knowledge and Perception of Climate Change among Apple Growers in Northwestern India”. In Journal of Ecological Anthropology. 10:4-18.

Vedwan, N. and R. E. Rhoades, (2001). "Climate Change in the Western Himalayas of India: A Study of Local Perception and Response”, in Climate Research, 19:109117.

Wenke, R. J. (1990). Patterns in Prehistory: Humankind's First Three Million Years. New York: Oxford University Press

West C. T. and M. Vasque-Leon. (2003). Testing Farmers' Perceptions of Climate Variability: A Case Study from the Sulphur Springs Valley, Arizona”, in S. Strauss and B. Orlove (eds.) Weather, Climate and Culture. Oxford: Berg Pp 233-250. 